\title{
Antioxidant, Cytotoxic, and Enzyme Inhibitory Activities of Agropyron repens and Crataegus monogyna Species
}

\author{
Ebru Deveci ${ }^{\mathbb{D}}$, Gulsen Tel Cayan² ${ }^{\mathbb{D}}$, Serdar Karakurt ${ }^{3}$ (D), Mehmet Emin Duru ${ }^{4}$ \\ 'Konya Technical University, Department of Chemistry and Chemical Processing Technologies, Konya, Turkey \\ 2Muğla Sıtkı Koçman University, Department of Chemistry and Chemical Processing Technologies, Muğla, Turkey \\ ${ }^{3}$ Selcuk University, Faculty of Science, Department of Biochemistry, Konya, Turkey \\ ${ }^{4}$ Muğla Sıtkı Koçman University, Faculty of Science, Department of Chemistry, Muğla, Turkey
}

ORCID IDs of the authors: E.D. 0000-0002-2597-9898; G.T.C. 0000-0002-1916-7391; S.K. 0000-0002-4449-6103; M.E.D. 0000-0001-7252-4880

Please cite this article as: Deveci E, Tel Cayan G, Karakurt S, Duru ME. Antioxidant, Cytotoxic, and Enzyme Inhibitory Activities of Agropyron repens and Crataegus monogyna Species. Eur J Biol 2020; 79(2): 98-105. DOI: 10.26650/EurJBiol.2020.0077

\begin{abstract}
Objective: The aim of this study was to investigate antioxidant, enzyme inhibitory and cytotoxic activities of Agropyron repens and Crataegus monogyna methanol extracts with total phenolic and flavonoid contents.

Materials and Methods: Total phenolic and flavonoid contents of $A$. repens and $C$. monogyna methanol extracts were measured according to Folin Ciocalteu and aluminum nitrate methods, respectively. Antioxidant and enzyme inhibitory activities of the methanol extracts were tested spectrophotometrically. Also, cytotoxic activities of the methanol extracts against DLD-1 and CCD-18Co were investigated by using Alamar Blue assay.

Results: $C$. monogyna methanol extract with the highest total phenolic and flavonoid contents $(68.13 \pm 0.34 \mu \mathrm{g} \mathrm{GAEs} / \mathrm{mg}$ extract and $36.91 \pm 0.17 \mu \mathrm{g} Q E s / m g$ extract, respectively) had the best antioxidant activity in $\beta$-carotene-linoleic acid (IC : $_{50}$ : $32.72 \pm 0.15 \mu \mathrm{g} / \mathrm{mL})$, CUPRAC $\left(A_{0.50}: 282.69 \pm 0.25 \mu \mathrm{g} / \mathrm{mL}\right), D^{\prime} P P H\left(I C_{50}: 71.69 \pm 0.85 \mu \mathrm{g} / \mathrm{mL}\right)$, and ABTS $+\left(\mathrm{IC}_{50}: 40.43 \pm 0.55 \mu \mathrm{g} /\right.$ $\mathrm{mL}$ ) assays. A. repens methanol extract showed the highest effect against $\mathrm{AChE}(18.73 \pm 0.47 \%), \mathrm{BChE}(37.59 \pm 1.07 \%)$, urease $(89.18 \pm 0.84 \%)$, a-glucosidase $(6.71 \pm 0.23 \%)$, whereas $C$. monogyna methanol extract showed the highest effect against tyrosinase $(30.52 \pm 1.00 \%)$ and $a$-amylase $(37.24 \pm 0.06 \%)$. Also, A. repens $\left(\mathrm{IC}_{50}: 57.38 \mu \mathrm{g} / \mathrm{mL}\right)$ and C. monogyna $\left(\mathrm{IC}_{50}: 54.04 \mu \mathrm{g} /\right.$ $\mathrm{mL}$ ) methanol extracts showed close cytotoxic activity on DLD-1.

Conclusion: Antioxidant, cytotoxic, and enzyme inhibitory activities of $A$. repens and C. monogyna methanol extracts were investigated with total phenolic and flavonoid contents in this study. The results obtained with this study strengthen the potential of the studied plants as a new source for the discovery of antioxidant, cytotoxic, and enzyme inhibitor agents.
\end{abstract}

Keywords: Agropyron repens, Crataegus monogyna, antioxidant activity, cytotoxic activity, enzyme inhibitory activity

\section{INTRODUCTION}

Pharmacologically, medicinal plants have always been at the forefront of almost all civilizations. Medicinal plants are used to treat diseases and prevent possible epidemics, and additionally to flavor and to preserve foods. Also, medicinal plants are considered as rich sources of traditional medicines, and most synthetic medicines are produced from these plants. Secondary metabolites produced by plants are generally respon- sible for the biological properties of plant species used worldwide $(1,2)$. Compounds such as alkaloids, tannins, flavonoids, and phenolics found in plants are therapeutic for human health $(3,4)$.

Agropyron species is a member of Poaceae. Agropyron repens (Quack grass) is known as 'Ayrık otu' in Turkey. It is often used in folk medicine as a diuretic in prostate disease, urinary infections, as well as calming of spasms and pain in the urinary tract (5). A. repens has been reported 
to be used in Bulgarian traditional medicine as antitussive, anti-inflammatory, and diuretic; in Kosovo traditional medicine as antirheumatic and antianemic; in Turkey traditional medicine to treat treatment of kidney stones and gastrointestinal diseases (6-8). A. repens was previously determined to contain phenol compounds, carbohydrates, pectins, saponins and to have anti-inflammatory, antiadhesive, and diuretic effects (9-11).

Crataegus species is a member of Rosaceae and widely grown in Europe, America, and Asia. The genus Crataegus consists of 200 species around the world and represented by 21 species in Turkey. Crataegus (Hawthorn) is known as 'Alıç' in Turkey (12). Crataegus (hawthorn) species are widely used in folk medicine in the therapy of diseases such as congestive heart failure, angina, hypertension, arrhythmia. Crataegus species have been reported to be used in traditional Chinese medicine to remove blood stasis, improve circulation, treat diarrhea, indigestion, hyperlipidemia, hypertension and abdominal pain; in European traditional medicine in the therapy of heart problems in associated with their antiatherosclerotic, cardiotonic, antispasmodic, and hypotensive properties; in Turkey traditional medicine as a diuretic agent for the treatment of intestinal disorders (13). It has been reported that Crataegus species indicated immunostimulant, radical scavenging, antiviral, anti-lipoperoxidant, antimicrobial, anti-inflammatory, antihyperlipidemic, hepatoprotective, gastroprotective, and hypoglycemic activities in relation to containing phenolic compounds, proanthocyanins, triterpenoids, and flavonoid glycosides $(12,14)$.

Investigating the effects of medicinal plants on health is important for the discovery or design of new drugs, and studies in this area have been increasing in recent years. Therefore, the aim of this study is to investigate the antioxidant, cytotoxic, and enzyme inhibitory activities of $A$. repens and Crataegus monogyna methanol extracts with total phenolic and flavonoid contents.

\section{MATERIALS AND METHODS}

\section{Plant Materials}

A. repens and C. monogyna were collected from Konya, Turkey in 2017. The plant species were identified by Dr. Ergün Kaya at Muğla Sıtkı Koçman University, Muğla, Turkey. The voucher specimen has been deposited at Plant Molecular Genetics and Biotechnology Laboratory, Department of Molecular Biology and Genetics, Muğla Sıtkı Koçman University with voucher no EK.1688 (for A. repens) and EK.1687 (for C. monogyna).

\section{Extraction}

The aerial parts of $A$. repens and C. monogyna were extracted with methanol at room temperature for $24 \mathrm{~h}$ and four times. Solvent was evaporated under vacuum by an evaporator to obtain the methanol extracts. All extracts were stored at $+4^{\circ} \mathrm{C}$ until analysis.

\section{Instruments}

Antioxidant and enzyme inhibitory tests were measured by using a 96-well microplate reader, SpectraMax 340PC384 (Molecular Devices, Silicon Valley, California, USA). Softmax PRO v5.2 software (Molecular Devices, Silicon Valley) was used to calculate and measure the bioactivity data. A 96-well microplate reader (MultiskanGo, Thermo Scientific Co., MA, USA) was used to analyze cytotoxic activity studies. Cytotoxic activity results were measured and calculated by using GraphPad Prism (GraphPad Software v5.0, USA).

\section{Total Phenolic and Flavonoid Contents}

The phenolic contents of extracts were tested based on the method reported by Slinkard and Singleton (15). Results were given as a microgram of gallic equivalents (GAEs) using the following equation that was obtained from standard gallic acid graph:

Absorbance $=0.0104[$ gallic acid $(\mu \mathrm{g})]-0.0263\left(r^{2}, 0.9974\right)$

Total flavonoid contents of extracts were measured by using the aluminum nitrate method (16). Results were given as microgram quercetin equivalents (QEs) using the following equation that was obtained from standard quercetin acid graph:

Absorbance $=0.0158[$ quercetin $(\mu \mathrm{g})]-0.0306\left(r^{2}, 0.9993\right)$

\section{Antioxidant Activity}

$\beta$-carotene-linoleic acid, metal chelating, cupric reducing antioxidant capacity (CUPRAC), 1,1-diphenyl-2-picrylhydrazyl free radical (DPPH'), and (3-ethylbenzothiazoline-6-sulfonic acid) diammonium salt cation radical (ABTS ${ }^{+}$) scavencing assays were performed for measurement of antioxidant activities of the extracts (17). The graph of the inhibition percentage (\%) versus the concentration $(\mu \mathrm{g} / \mathrm{mL})$ was used to calculate the $\mathrm{IC}_{50}$ values of the extracts. The graph of the absorbance versus the concentration $(\mu \mathrm{g} / \mathrm{mL})$ was used to calculate 0.50 absorbance $\left(A_{0.5}\right)$ values of the extracts. The antioxidant activity results were stated as $50 \%$ inhibition concentration $\left(\mathrm{IC}_{50}\right)$ for $\beta$-carotene-linoleic acid, ABTS and DPPH scavenging, inhibition percentage (\%) at $400 \mu \mathrm{g} / \mathrm{mL}$ concentration for metal chelating assay and $A_{0.50}$ which corresponds to the concentration producing 0.500 absorbance for CUPRAC assay.

\section{Enzyme Inhibitory Activity}

Acetylcholinesterase (AChE), butyrylcholinesterase (BChE), urease, and tyrosinase inhibitory activities of the extracts were carried out as reported in our previous study (18). a-Amylase and a-glucosidase inhibitory activities were screened according to the method previously reported by Deveci et al. (19). Galantamine, Kojic acid, Thiourea and Acarbose were used as standards. The enzyme inhibitory activity results were stated $\mathrm{as} \mathrm{IC}_{50}$ and inhibition percentages (\%).

\section{Cell Culture}

DLD-1 (colorectal cancer), and CCD-18Co (human colon fibroblast cell line) were cultivated in RPMI-1640 and EMEM growth mediums (ATCC, Virginia, USA), respectively and incubated with $1 \%$ penicillin/streptomycin, $10 \%$ fetal bovine serum (FBS), $2 \mathrm{mM}$ L-glutamine (Sigma, St. Louis, Missouri, USA) in $5 \% \mathrm{CO}_{2}$ at $37^{\circ} \mathrm{C}$ and $90-95 \%$ humidity.

\section{Cell Viability Assay}

$1 \times 10^{4}$ cells were put into 96 -well plate with growth medium and incubated in $5 \% \mathrm{CO}_{2}$ at $37^{\circ} \mathrm{C}$ for $24 \mathrm{~h}$ until attached to the 
bottom. Then, different concentrations (between $1 \mu \mathrm{g} / \mathrm{mL}$ and $1000 \mu \mathrm{g} / \mathrm{mL}$ ) of the extracts were added to each well. Viability and proliferation of the cells were tested according to the previously described Alamar Blue assay (20). The results were measured by using 96-well microplate reader at $570 \mathrm{~nm}$ and $610 \mathrm{~nm}$. The sigmoidal plot of the inhibition rate (\%) versus the log concentration $(\mu \mathrm{g} / \mathrm{mL})$ was used to calculate the $\mathrm{IC}_{50}$ values of the extracts.

\section{Statistical Analysis}

Antioxidant, cytotoxic, and enzyme inhibitory activity results were the average of three parallel sample measurements. The data were registered as the mean \pm S.E.M.

\section{RESULTS}

\section{Total Phenolic and Flavonoid Contents}

Total phenolic and flavonoid contents of $A$. repens and $C$. monogyna methanol extracts were measured according to
Folin Ciocalteu and aluminum nitrate methods, respectively. Total phenolic contents of $A$. repens and C. monogyna methanol extracts were calculated as $24.57 \pm 0.22$ and $68.13 \pm 0.34 \mu \mathrm{g}$ GAEs/mg extract. Total flavonoid contents of $A$. repens and $C$. monogyna methanol extracts were recorded as $9.31 \pm 0.41$ and 36.91 $\pm 0.17 \mu \mathrm{g}$ QEs/mg extract (Table 1).

\section{Antioxidant Activity}

Antioxidants have different mechanisms of action, so more than one method is need to be used to test antioxidant properties. Therefore, antioxidant activities of $A$. repens and C. monogyna methanol extracts were screened by using five different assays, namely, $\beta$-carotene-linoleic acid, metal chelating, CUPRAC, scavenging of ABTS cation radical and DPPH free radical assays and results are summarized in Table 2.

$\beta$-carotene-linoleic acid method is an important test system that demonstrates the ability of antioxidant compounds to inhibit linoleic acid oxidation. The degree of the bleaching caused

Table 1. Total phenolic and flavonoid contents of the extracts ${ }^{\mathrm{a}}$.

Total phenolic content ( $\mu \mathrm{g}$ GAEs/mg extract) $)^{\mathrm{b}}$

\section{Total flavonoid contents ( $\mu \mathrm{g}$ QEs/mg extract) ${ }^{c}$}

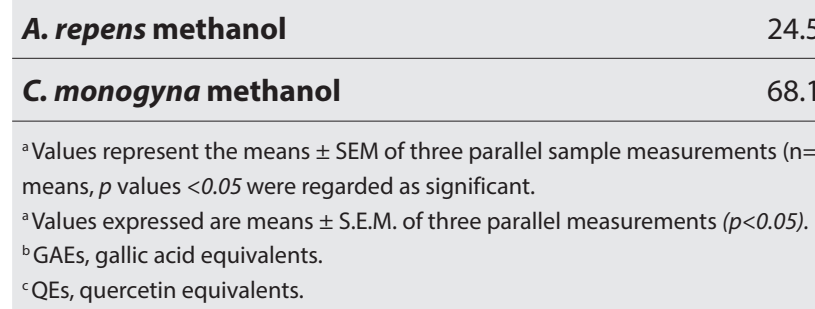

Table 2. Antioxidant activities of the extracts.

\begin{tabular}{|c|c|c|c|c|c|}
\hline & \multicolumn{5}{|c|}{ Antioxidant Activity } \\
\hline & $\begin{array}{c}\boldsymbol{\beta} \text {-carotene-linoleic } \\
\text { acid assay }\end{array}$ & DPPH· assay & ABTS ${ }^{++}$assay & CUPRAC assay & $\begin{array}{c}\text { Metal chelating } \\
\text { assay }\end{array}$ \\
\hline Extracts & $\mathrm{IC}_{50}(\boldsymbol{\mu g} / \mathrm{mL})^{\mathrm{a}}$ & $\mathrm{IC}_{50}(\boldsymbol{\mu g} / \mathbf{m L})^{\mathrm{a}}$ & $I C_{50}(\mu \mathrm{g} / \mathrm{mL})^{\mathrm{a}}$ & $A_{0.50}(\mu \mathrm{g} / \mathbf{m L})^{b}$ & Inhibition (\%) ${ }^{c}$ \\
\hline A. repens methanol & $77.62 \pm 0.09$ & $>400$ & $127.78 \pm 0.99$ & $>400$ & $13.09 \pm 0.99$ \\
\hline C. monogyna methanol & $32.72 \pm 0.15$ & $71.69 \pm 0.85$ & $40.43 \pm 0.55$ & $282.69 \pm 0.25$ & $N A^{e}$ \\
\hline a-Tocopherol ${ }^{d}$ & $2.10 \pm 0.08$ & $37.18 \pm 0.41$ & $38.51 \pm 0.54$ & $66.72 \pm 0.81$ & $N T^{f}$ \\
\hline $\mathbf{B H A}^{d}$ & $1.34 \pm 0.04$ & $19.80 \pm 0.36$ & $11.82 \pm 0.09$ & $24.40 \pm 0.69$ & $N T^{f}$ \\
\hline EDTA $^{d}$ & $N T^{f}$ & $N T^{f}$ & $N T^{f}$ & $N T^{f}$ & $95.20 \pm 0.13$ \\
\hline $\begin{array}{l}\text { a: IC }{ }_{50} \text { values represent the means } \\
p \text { values }<0.05 \text { were regarded as s } \\
\text { b: } A_{0.50} \text { values represent the means } \\
c: \text { Inhibition } \% \text { of } 400 \mu \mathrm{g} / \mathrm{mL} \text { conc } \\
\text { d: Standards } \\
\text { e: NA: Not active. } \\
\text { f: NT: Not tested. }\end{array}$ & $\begin{array}{l}\text { M of three parallel measurem } \\
\text { icant. } \\
\text { EM of three parallel measuren } \\
\text { ation of the extracts. }\end{array}$ & $\begin{array}{l}(n=3) \text { analyzed } 3 \text { ti } \\
s(p<0.05) .\end{array}$ & 5. T test was used to & termine significant di & rences between means, \\
\hline
\end{tabular}


a)

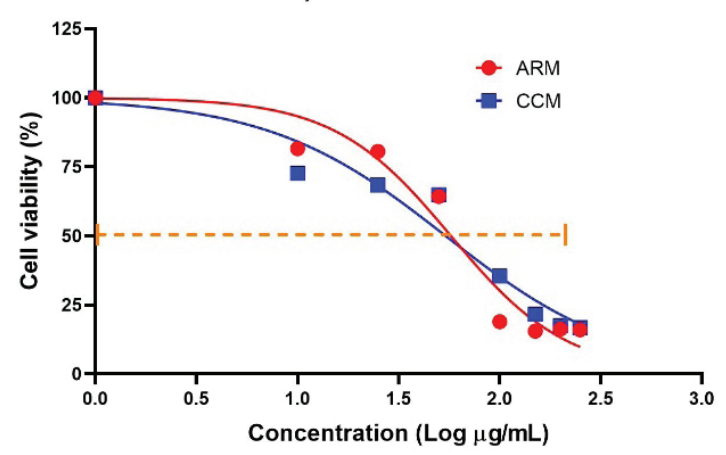

c)

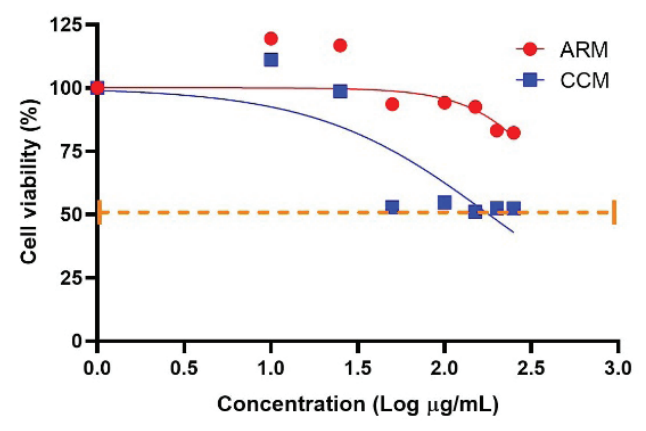

b)

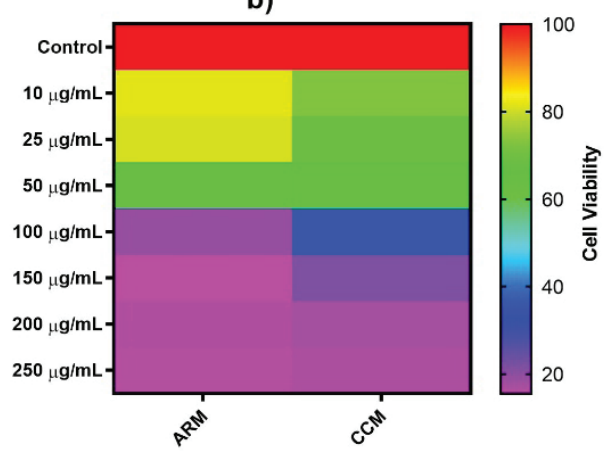

d)

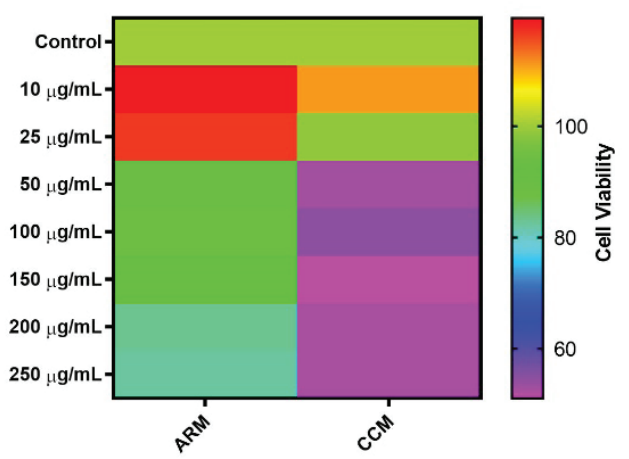

Figure 1. Cytotoxic effects of $A$. repens and C. monogyna methanol extracts on DLD-1 and CCD-18Co a) IC ${ }_{50}$ values on DLD-1 b) Heat Map

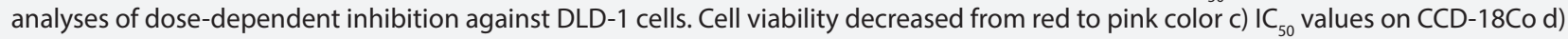
Heat Map analyses of dose-dependent inhibition against CCD-18Co. Cell viability decreased from green to pink color. ARM: A. repens methanol extract, CMM: C. monogyna methanol extract.

by lipid peroxyl radicals formed in the method in the color of $\beta$-carotene is inhibited by antioxidant compounds are tested. $\mathrm{IC}_{50}$ values of $A$. repens and $C$. monogyna methanol extracts were found as $77.62 \pm 0.09$ and $32.72 \pm 0.15 \mu \mathrm{g} / \mathrm{mL}$ in the $\beta$-carotene-linoleic acid assay.

$\mathrm{ABTS}^{+}$and $\mathrm{DPPH} \cdot$ radicals are the most widely used radicals in determining of radical scavenging activities. As it is seen in Table 2 , the best scavenging activities on $\mathrm{ABTS}^{+}\left(\mathrm{IC}_{50}: 40.43 \pm 0.55 \mu \mathrm{g} /\right.$ $\mathrm{mL})$ and $\mathrm{DPPH}^{\cdot}\left(\mathrm{IC}_{50}: 71.69 \pm 0.85 \mu \mathrm{g} / \mathrm{mL}\right)$ radicals were observed in C. monogyna methanol extract. Also, C. monogyna methanol extract indicated near-standard activity in ABTS ${ }^{+}$assay.

The reducing power is an important indicator to evaluate antioxidant activity and the electron donation capabilities of the methanol extracts were determined by using the CUPRAC method. When compared to the standards, both methanol extracts showed low cupric reducing power.

Transition metals accumulate in the body at high rates, contributing to oxidative damage and thus causing various abnormalities. Therefore, metal chelating activity is of great importance in explaining of antioxidant activity. When $A$. repens methanol extract exhibited low metal chelating activity with an inhibition
Table 3. Cytotoxic activities of the extracts.

\begin{tabular}{lcc}
\hline & DLD-1 & CCD-18Co \\
\hline Extracts & IC $_{50}(\boldsymbol{\mu g} / \mathbf{m L})$ & IC $_{50}(\boldsymbol{\mu g} / \mathbf{m L})$ \\
\hline A. repens methanol & 57.38 & 543.30 \\
\hline C. monogyna methanol & 54.04 & 179.60 \\
\hline
\end{tabular}

value of $13.09 \pm 0.99 \%$ at $400 \mu \mathrm{g} / \mathrm{mL}$ concentration, C. monogyna methanol extract showed no activity.

\section{Cytotoxic Activity}

Cytotoxic activities of $A$. repens and C. monogyna methanol extracts were tested on DLD-1 (colorectal cancer) and CCD-18Co (human colon fibroblast cell line) according to Alamar Blue assay. Figure 1 represents the cytotoxic effects of the methanol extracts on DLD-1 and CCD-18Co. Table 3 shows the calculated $\mathrm{IC}_{50}$ values of the methanol extracts. As seen in Figure 1a and $1 \mathrm{C}$, the methanol extracts inhibited the viability of DLD-1 and CCD-18Co dose-dependently. A. repens $\left(\mathrm{IC}_{50}: 57.38 \mu \mathrm{g} / \mathrm{mL}\right)$ and C. monogyna $\left(\mathrm{IC}_{50}: 54.04 \mu \mathrm{g} / \mathrm{mL}\right)$ methanol extracts showed similar cytotoxic activity on DLD-1. 


\section{Enzyme Inhibitory Activity}

Cholinesterase inhibitory activities of $A$. repens and C. monogyna methanol extracts were screened according to the Ellman method and the results are given in Table 4. A. repens displayed the best inhibitory activity against AChE $(18.73 \pm 0.47 \%)$ and BChE $(37.59 \pm 1.07 \%)$ at $200 \mu \mathrm{g} / \mathrm{mL}$ concentration.

Dopachrome method was used to test tyrosinase inhibitory activities of $A$. repens and $C$. monogyna methanol extracts. As it is given in Table 4, C. monogyna methanol extract showed low inhibitory activity against tyrosinase while $A$. repens methanol extract exhibited no activity.

Indophenol method was used for the measurement of urease inhibitory activity of $A$. repens and C. monogyna methanol extracts and results are summarized in Table 4. A. repens methanol extract $(89.18 \pm 0.84 \%)$ was found as better urease inhibitor by comparison with thiourea $(78.93 \pm 0.18 \%)$ at $200 \mu \mathrm{g} / \mathrm{mL}$ concentration.

Antidiabetic activities of $A$. repens and C. monogyna methanol extracts on a-amylase and a-glucosidase were determined. As it presented in Table 4, the highest a-amylase inhibitory activity was found in C. monogyna methanol extract (37.24 \pm 0.06 $\%$ at $500 \mu \mathrm{g} / \mathrm{mL}$ concentration) while the best a-glucosidase inhibitory activity was observed in $A$. repens methanol extract ( $6.71 \pm 0.23 \%$ at $250 \mu \mathrm{g} / \mathrm{mL}$ concentration).

\section{DISCUSSION}

Medicinal plants, besides being used as taste, color, aroma and preservatives in foods for centuries, are excellent sources of natural antioxidants, and their bioactive compounds, especially phenolic substances, have the potential to reduce the risk of degenerative diseases such as diabetes, obesity, cardiovascular diseases and cancer (21). Antioxidant, cytotoxic, and enzyme inhibitory activities of $A$. repens and C. monogyna methanol extracts were investigated with total phenolic and flavonoid contents in this current study.

Phenolic compounds are one of the largest and most common secondary metabolite groups in the plant world with more than 8000 identified phenolic structures (22) Phenolic compounds can be found in all organs of plants and are involved in many functions, from skeletal components of different tissues to pigmentation (23). Phenolic compounds have diverse biological functions such as inhibition of lipid peroxidation, antioxidant and antimicrobial activities, inhibition of carcinogenesis, direct constrictive action on capillaries (24). Flavonoids are an essential group of naturally occurring phenolic compounds found in all vascular plants. It was well documented that flavonoids had antioxidant, cardioprotective, antidiabetic, antiinflammatory, anti-allergic, antiviral, and anticancer effects (25). Plant phenolics and flavonoids have received greater attention since they have various biological properties. The highest amounts of total phenolic and flavonoid contents were found in C. monogyna methanol extract. Öztürk and Tunçel (26) reported the total phenolic contents of the methanol, ethyl acetate, 
aqueous, and infusion extracts of $C$. monogyna in the range of 108.65 and $343.54 \mathrm{mg} \mathrm{GAE} / \mathrm{g}$ extract. In a different study, total phenolic (361.39 $\pm 3.78-398.48 \pm 0.98 \mathrm{mg} \mathrm{GAE} / \mathrm{g}$ extract) and flavonoid (13.69 $\pm 0.51-23.87 \pm 2.74 \mathrm{mg} \mathrm{QE} / \mathrm{g}$ extract) contents of C. orientalis, C. monogyna, C. pontica, C. turcicus, C. rhipidophylla were investigated (12). Cosmulescu et al. found contents of $203.01 \pm 9.56 \mathrm{mg} \mathrm{GAE} / 100 \mathrm{~g} \mathrm{FW}$ phenolics and $147.98 \pm 7.29 \mathrm{mg}$ $\mathrm{QE} / 100 \mathrm{~g}$ FW flavonoids in the methanol extract of $C$. monogyna (27). Total phenolic content of $A$. repens methanol extract was calculated as 743 GAE mg/100 g extract by Dogan et al. (28).

Oxidative stress plays an important role in the development and initiation of many diseases, comprising autoimmune diseases, inflammation, Parkinson's and neurodegenerative diseases, aging, cataracts, arteriosclerosis, and cancer (29). Studies have proven that oxidative damage is effective in the development of age-related and chronic diseases, and dietary antioxidant supplementation counteracts it and reduces the risk of disease (30). Antioxidants are substances that delay or prevent oxidation of an oxidizable substrate at low concentrations (31). In this study, antioxidant activities of $A$. repens and C. monogyna methanol extracts were screened by using five different assays and C. monogyna methanol extract was recorded to have the highest antioxidant activity in all activity assays excluding metal chelating assay. The highest antioxidant activity could be connected with the highest level of total phenolic and flavonoid contents. Many previous studies have proved that there is a positive relationship between the levels of total phenolic and flavonoid contents and antioxidant activity $(12,18)$. There are studies on the antioxidant properties of $A$. repens and $C$. monogyna species in the literature. Scavenging activity of DPPH was found as $0.32 \pm 0.01 \mathrm{mmol}$ Trolox/100 $\mathrm{g} \mathrm{FW}$ in C. monogyna methanol extract (27). Antioxidant activity of the water, $80 \%$ ethanol: water and ethanol extracts of $C$. monogyna were studied by Nunes et al. (32). When $80 \%$ ethanol: water extract exhibited the highest activity in total antioxidant activity (243.31 $\pm 9.61 \mathrm{AAE} / \mathrm{g} \mathrm{dw})$, reducing power (177.86 \pm 7.54 $\mathrm{mg} \mathrm{TE} / \mathrm{g} \mathrm{dw})$, ferric reducing antioxidant power $(225.52 \pm 10.91$ $\mathrm{mg} \mathrm{TE} / \mathrm{g} \mathrm{dw})$ assays, the water extract $(61.56 \pm 4.00 \mu \mathrm{g}$ sample/ $\mathrm{mL}$ ) in DPPH radical scavenging assay. Rocchetti et al. reported the decoction, infusion, and methanolic extracts of leaves and twig of C. tanacetifolia, C. szovitsii, C. orientalis by using phosphomolybdenum (1.18 $\pm 0.06-3.45 \pm 0.09 \mathrm{mmol} \mathrm{TE} / \mathrm{g})$, ABTS (81.35 $\pm 5.28-515.54 \pm 6.29 \mathrm{mg} \mathrm{TE} / \mathrm{g}), \mathrm{DPPH}$ (74.20 $\pm 1.26-$ $393.69 \pm 0.48 \mathrm{mg} \mathrm{TE} / \mathrm{g})$, CUPRAC $(200.51 \pm 2.71-708.09 \pm 13.35$ $\mathrm{mg}$ TE/g), FRAP $(97.84 \pm 1.10-399.02 \pm 2.03 \mathrm{mg} \mathrm{TE} / \mathrm{g})$ and metal chelating (11.90 $\pm 1.68-48.95 \pm 1.01 \mathrm{mg}$ EDTAE/g) assays (33). In a different report, antioxidant properties of $50 \%$ ethanol, $70 \%$ methanol, and water extracts of C. monogyna were tested according to DPPH and FRAP assays. 50\% ethanol extract was found to have the highest activity in DPPH and FRAP assays with the value of $1955.9 \pm 2.8$ and $1989.8 \pm 1.1 \mathrm{mM}$ Trolox/g, respectively (34). In the research of Ferysiuk et al., water, aqueous ethanol $(50: 50)$ and ethanol extracts of $A$. repens scavenged $1.77 \pm 0.41,2.92 \pm 0.18,4.42 \pm 0.3 \%$ of $\mathrm{DPPH}^{\cdot}$ and $1.23 \pm 0.17,4.85 \pm 0.22,3.6 \pm 0.15 \%$ of $\mathrm{ABTS}^{+}$, respectively (5).
Colorectal cancer ranks 3rd after lung and breast cancer deaths in women, and lung and prostate cancer deaths in men. Considering the etiology of colorectal cancer, it is basically the genetic change process of the epithelial cells in the colon mucosa. The factors that trigger colon cancer include susceptibility to mutagenic effects, red meat consumption, bile acids, and insufficient intake of vitamins and minerals (35). Although the main treatment is surgery, recurrences occur in most of the patients within the first 3 years after surgery with only surgical treatment (36). Many different treatment modalities are used in cancer treatment to reduce mortality and increase survival. These can be listed as surgery, radiotherapy, chemotherapy, hormone therapy and new treatment methods, immunotherapy, signal transduction system inhibitors, gene therapy, and angiogenesis inhibitors. Chemotherapy is a form of treatment aimed mainly at killing cancer cells. However, the effectiveness of current chemotherapy agents in different cancer types is limited $(37,38)$. For cancer treatment, many drugs, and new treatment methods have been developed in recent years, and studies to obtain new, natural and side effects free drugs from plants have gained importance. $A$. repens and $C$. monogyna methanol extracts showed close cytotoxic activity on DLD-1. There are only two reports on the literature related with cytotoxic activity of Crataegus species. The \% inhibition values of HCT116 (colorectal cancer) by Crataegus L. polysaccharide extract were reported as in a range from $20 \%$ to $80 \%$ between 125 and $1000 \mu \mathrm{g} / \mathrm{mL}$ concentrations (39). Ganie et al. revealed that $C$. songarica methanol, ethanol and ethyl acetate extracts inhibited $\sim 80 \%, 85 \%, 75 \%$ of SW480 (colorectal cancer) at 80 $\mu \mathrm{g} / \mathrm{mL}$ concentration (40).

In Alzheimer's disease (AD), the acetylcholine level decreases with the loss of neurons and axons. For this reason, increasing the acetylcholine level is important in the therapy of AD. Acetylcholine level can be increased by suppressing cholinesterase enzymes that break down acetylcholine. AChE and $B C h E$ are enzymes that are encoded by different genes but differ from each other, especially due to their substrate selectivity and differences in some catalytic mechanisms. Studies have reported that increases in acetylcholine levels due to cholinesterase inhibition may improve unconsciousness in the early stages of $A D(41,42)$. Tyrosinase is an important enzyme in hyperpigmentation problems such as skin spots caused by excessive melanin synthesis in the body and such as psoriasis and vitiligo caused by insufficient melanin synthesis. Agents that inhibit this enzyme can be used in the treatment of hyperpigmentation problems $(43,44)$. Urease is an enzyme catalyse the hydrolysis of urea to ammonia and bicarbonate. Inhibition of urease is especially important in the treatment of urinary and gastrointestinal tract infections. Urease inhibitors are very important for Helicobacter pylori, an anaerobic bacterium that has recently caused stomach reflux, ulcers and gastritis. In fact, urease activity has an essential role in buffering the acidic $\mathrm{pH}$ in the stomach, in food intake, and in enhancing the ability of $H$. pylori to colonize the gastric epithelium. Urease inhibition is very important for the treatment of diseases associated with $H$. pylori $(45,46)$. Diabetes mellitus, characterized by insulin 
deficiency or ineffectiveness, is a lifelong metabolic disease. In type 2 diabetes, the level of sugar in the blood increases due to both insufficient insulin secretion and decreased insulin sensitivity (47). One of the treatment methods to reduce blood sugar is to delay the passage of glucose into the blood by inhibiting the activity of carbohydrate digestive enzymes such as a-glucosidase and a-amylase in the digestive system, or to allow them to pass into the blood regularly (48). According to obtained results, $A$. repens methanol extract displayed the highest effect against $\mathrm{AChE}, \mathrm{BChE}$, urease, a-glucosidase enzymes whereas C. monogyna methanol extract showed the highest effect against tyrosinase and a-amylase enzymes. Previously, tyrosinase inhibition values of $C$. monogyna and $C$. oxyacantha were reported as $\sim 40 \%$ and $\sim 50 \%$, respectively (49). a-Amylase $\left(I C_{50}: 10.71 \pm 0.11 \mathrm{mg} / \mathrm{mL}\right)$, a-glucosidase $\left(I C_{50}\right.$ : $10.72 \pm 0.43 \mathrm{mg} / \mathrm{mL}), A C h E\left(\mathrm{IC}_{50}: 69.59 \pm 1.12 \mathrm{mg} / \mathrm{mL}\right)$ and $B C h E$ (IC 50 : $132.70 \pm 2.12 \mathrm{mg} / \mathrm{mL}$ ) inhibitory activities of Crataegus L. methanol:water extract were investigated by Nowicka and Wojdylo (50). The decoction, infusion and methanolic extracts of twig and leaves of C. tanacetifolia, C. szovitsii, C. orientalis were tested for their inhibitory activities against AChE (3.62 $\pm 0.25-4.33 \pm 0.05 \mathrm{mg}$ GALAE/g), BChE (1.43 $\pm 0.05-$ $5.21 \pm 0.07 \mathrm{mg}$ GALAE/g), tyrosinase $(9.80 \pm 2.39-128.78 \pm 0.94$ $\mathrm{mg} \mathrm{KAE} / \mathrm{g})$, a-amylase (0.11 $\pm 0.01-0.66 \pm 0.02 \mathrm{mmol} \mathrm{ACAE} / \mathrm{g})$ and a-glucosidase (3.01 $\pm 0.11-33.57 \pm 0.02 \mathrm{mmol} A C A E / g)(27)$. This study can be assumed as the first investigation on $\mathrm{AChE}, \mathrm{BChE}$, a-amylase, a-glucosidase, and urease inhibitory activities of $A$. repens and $C$. monogyna methanol extracts.

\section{CONCLUSION}

Antioxidant, cytotoxic, and enzyme inhibitory activities of $A$. repens and $C$. monogyna methanol extracts were investigated with total phenolic and flavonoid contents in this current study. It was determined that C. monogyna methanol extract with the highest total phenolic and flavonoid contents had the best antioxidant activity in all studied assays except metal chelating assay. When the extracts showed moderate enzyme inhibitory activities, $A$. repens methanol extract showed superior inhibitory activity against urease enzyme. Also, A. repens and C. monogyna methanol extracts showed close cytotoxic activity on DLD-1. This study can be considered as the first investigation on cytotoxic and enzyme inhibitory activities of $A$. repens and C. monogyna species. It is thought that this study will further contribute to the biological values of these plants, which are used for different purposes in folk medicines.

Peer-review: Externally peer-reviewed.

Authors Contributions: Concept: E.D., G.T.C.; Design: E.D., G.T.C., S.K.; Supervision: E.D. G.T.C.; Materials: E.D., G.T.C., M.E.D., S.K.; Data Collection and/or Processing: E.D., G.T.C., S.K.; Analysis and/or Interpretation: E.D., G.T.C., S.K., M.E.D.; Literature Search: E.D., G.T.C.; Writing: E.D., G.T.C.; Critical Reviews: E.D., G.T.C., S.K., M.E.D.

Conflict of Interest: The authors declare that they have no conflicts of interest to disclose.
Financial Disclosure: There are no funders to report for this submission.

Acknowledgements: Authors would like to thank Dr. Ergün Kaya (Faculty of Science, Department of Molecular Biology and Genetics, Muğla Sıtkı Koçman University) for the identification of the plant samples.

\section{REFERENCES}

1. Dar RA, Shahnawaz M, Qazi PH. General overview of medicinal plants: A review. J Phytopharmacol 2017; 6: 349-51.

2. Top R, Erden $\mathrm{Y}$, Tekin S. The investigation of antioxidant and anticancer effects of some importance medical plants. BEU J Sci 2019; 8(2): 435-42.

3. Ginwala R, Bhavsar R, Chigbu DI, Jain P, Khan ZK. Potential role of flavonoids in treating chronic inflammatory diseases with a special focus on the anti-inflammatory activity of apigenin. Antioxidants 2019; 8(2): e35.

4. Rawat D, Shrivastava S, Naik RA, Chhonker SK, Mehrotra A, Koiri RK. An overview of natural plant products in the treatment of hepatocellular carcinoma. Anticancer Agents Med Chem 2018; 18(3): 1838-59.

5. Ferysiuk K, Wójciak KM. The spectrophotometric analysis of antioxidant properties of selected herbs in vision-pro ${ }^{\mathrm{TM}}$ uv-vis. Appl Comput Sci 2019; 15: 49-62.

6. Leporatti ML, Ivancheva S. Preliminary comparative analysis of medicinal plants used in the traditional medicine of Bulgaria and Italy. J Ethnopharmacol 2003; 87:123-42.

7. Mustafa B, Hajdari A, Krasniqi F, Hoxha E, Ademi H, Quave CL, et al. Medical etnobotany of the Albanian Alps in Kosovo. J Ethnobiol Ethnomed 2012; 8:6.

8. Sargın SA, Akçicek E, Selvi S. An ethnobotanical study of medicinal plants used by the local people of Alaşehir (Manisa) in Turkey. J Ethnopharmacol 2013; 150:860-74.

9. Grases F, Ramis M, Costa-Bauza A, March JG. Effect of Herniaria hirsuta and Agropyron repens on calcium oxalate urolithiasis risk in rats. J Ethnopharmacol 1995; 45: 211-4.

10. Mascolo N, Autore G, Capasso F, Menghini A, Fasulo MP. Biological screening of Italian medicinal plants for anti-inflammatory activity. Phytother Res 1987; 1: 28-31.

11. Rafsanjany $N$, Lechtenberg $M$, Petereit $F$, Hensel $A$. Antiadhesion as a functional concept for protection against uropathogenic Escherichia coli: In vitro studies with traditionally used plants with antiadhesive activity against uropathognic Escherichia coli. J Ethnopharmacol 2013; 145: 591-7.

12. Bardakci H, Celep E, Gözet T, Kan Y, Kırmızıbekmez H. Phytochemical characterization and antioxidant activities of the fruit extracts of several Crataegus taxa. S Afr J Bot 2019; 124: 5-13.

13. Edwards JE, Brown PN, Talent N, Dickinson TA, Shipley PR. A review of the chemistry of the genus Crataegus. Phytochemistry 2012; 79: 5-26.

14. Venskutonis PR. Phytochemical composition and bioactivities of hawthorn (Crataegus spp.): a review of recent research advances. J Food Bioact 2018; 4: 69-87.

15. Slinkard K, Singleton VL. Total phenol analyses: Automation and comparison with manual methods. Am J Enol Vitic 1977; 28: 49-55.

16. Park YK, Koo MH, Ikegaki M, Contado JL. Comparison of the flavonoid aglycone contents of Apis mellifera propolis from various regions of Brazil. Braz Arch Biol Technol 1997; 40: 97-106.

17. Çayan F, Tel-Çayan G, Deveci E, Öztürk M, Duru ME. Chemical profile, in vitro enzyme inhibitory, and antioxidant properties of Stereum species (Agaricomycetes) from Turkey. Int J Med Mushrooms 2019; 21(11): 1075-87. 
18. Deveci E, Tel-Çayan G, Duru ME, Öztürk M. Phytochemical contents, antioxidant effects, and inhibitory activities of key enzymes associated with Alzheimer's disease, ulcer, and skin disorders of Sideritis albiflora and Sideritis leptoclada. J Food Biochem 2019; 43: e13078.

19. Deveci E, Tel Cayan G, Duru ME. In vitro antidiabetic activity of seven medicinal plants naturally growing in Turkey. Eur J Biol 2020; 79: 23-8.

20. Karakurt S, Adali O. Tannic acid inhibits proliferation, migration, invasion of prostate cancer and modulates drug metabolizing and antioxidant enzymes. Anticancer Agents Med Chem 2016; 16(6): 781-9.

21. Patch CS, Sullivan DR, Fenech M. Health benefits of herbs and spices: Cardiovascular disease. Med J Aust 2006; 185(4): 7-9.

22. Tsao R. Chemistry and biochemistry of dietary polyphenols. Nutrients 2010; 2(12): 1231-46.

23. Ignat I, Volf I, Popa VI. A critical review of methods for characterisation of polyphenolic compounds in fruits and vegetables. Food Chem 2011; 126: 1821-35.

24. Tanase C, Cosarca S, Muntean DL. A critical review of phenolic compounds extracted from the bark of woody vascular plants and their potential biological activity. Molecules 2019; 24(6): 1182.

25. Karak P. Biological activities of flavonoids: an overview. Int J Pharm Sci Res 2019; 10(4): 1567-74.

26. Öztürk N, Tunçel M. Assessment of phenolic acid content and in vitro antiradical characteristics of hawthorn. J Med Food 2011; 14(6): 664-9.

27. Cosmulescu S, Trandafir I, Nour V. Phenolic acids and flavonoids profiles of extracts from edible wild fruits and their antioxidant properties. Int J Food Prop 2017; 20(12): 3124-34.

28. Dogan S, Diken ME, Dogan M. Antioxidant, phenolic and protein contents of some medicinal plants. J Med Plants Res 2010; 4(23): 2566-73.

29. Lukyanova LD, Storozheva ZI, Proshin AT. Corrective effect of flavonoid containing preparation extralife on the development of Parkinson's syndrome. Bull Exp Biol Med 2007; 144: 42-5.

30. Ghasemzadeh A, Ghasemzadeh N. Flavonoids and phenolic acids: Role and biochemical activity in plants and human. J Med Plants Res 2011; 5(31): 6697-703.

31. Lucio M, Nunes C, Gaspar D, Ferreira H, Lima JLFC, Reis S. Antioxidant activity of vitamin $\mathrm{E}$ and Trolox: understanding of the factors that govern lipid peroxidation studies in vitro. Food Biophys 2009; 4: 312-20.

32. Nunes R, Pasko P, Tyszka-Czochara M, Szewczyk A, Szlosarczyk M, Carvalho IS. Antibacterial, antioxidant and anti-proliferative properties and zinc content of five south Portugal herbs. Pharm Biol 2016; 55(1): 114-23.

33. Rocchetti G, Senizza B, Zengin G, Mahomodally MF, Senkardes I, Lobine $\mathrm{D}$, et al. Untargeted metabolomic profiling of three Crataegus species (hawthorn) and their in vitro biological activities. J Sci Food Agric 2020; 100(5): 1998-2006.

34. Parzhanova AB, Petkova N, Ivanov IG, Ivanova SD. Evaluation of biologically active substance and antioxidant potential of medicinal plants extracts for food and cosmetic purposes. J Pharm Sci Res 2018; 10(7): 1804-9.
35. Rostami S. M.Sc Thesis. Investigation of antiproliferative and antiinflammatory effects of common and endemic species of plants. Department of Biology, Institute of Science, Gazi University, Ankara, Turkey, 2013.

36. Doğan M, Akbulut H. Adjuvant Treatment of Colorectal Cancer. Turkiye Klinikleri J Med Oncol 2009; 2(3): 49-57.

37. Dellabona P, Moro M, Crosti MC, Casorati G, Corti A. Vascular attack and immunotherapy: a 'two hits' approach to improve biological treatment of cancer. Gene Ther 1999; 6: 153-4.

38. Terrero MN, Li S. Growth factor receptors: targets for gene therapy and immunotherapy for cancer treatment. Gene Ther Mol Biol 2004; 8: 175-80.

39. Ma L, Xu GB, Tang X, Zhang C, Zhao W, Wang J, et al. Anti-cancer potential of polysaccharide extracted from hawthorn (Crataegus.) on human colon cancer cell line HCT116 via cell cycle arrest and apoptosis. J Funct Foods 2020; 64: 103677.

40. Ganie SA, Dar TA, Zargar S, Bhat AH, Dar KB, Masood A, et al. Crataegus songarica methanolic extract accelerates enzymatic status in kidney and heart tissue damage in albino rats and its in vitro cytotoxic activity. Pharm Biol 2015; 54: 1246-54.

41. Howes MJR, Houghton PJ, Perry NSL. Plants wth tradtonal uses and actvtes, relevant to the management of Alzhemer's dsease and other cogntve dsorders. Phytother Res 2003; 17(1): 1-18.

42. Alkan HÖ, Zengin G, Kaşık G. Antioxidant and in vitro some enzyme inhibitory activities of methanolic extract of cultivated Lentinula edodes. J Fungus 2017; 8(2): 90-8.

43. Chang TM. Tyrosinase and tyrosinase inhibitors. J Biocatal Biotransformation 2012; 1: 2.

44. Gholamhoseinian A, ZohreRazmi Z. Screening the methanolic extracts of some plants for tyrosinase inhibitory activity. Toxicol Environ Chem 2012; 94: 310-8.

45. Baltas N, Karaoglu S, Tarakcı C, Kolayli S. Effect of propolis in gastric disorders: inhibition studies on the growth of Helicobacter pylori and production of its urease. J Enzyme Inhib Med Chem 2016; 31(S2): 46-50.

46. Baltas N, Yildiz O, Kolayli S. Inhibition properties of propolis extracts to some clinically important enzymes. J Enzyme Inhib Med Chem 2016; 31: 52-5.

47. Taslimi P, Gulçin İ. Antidiabetic potential: in vitro inhibition effects of some natural phenolic compounds on a-glycosidase and a-amylase enzymes. J Biochem Mol Toxicol 2017; 31(10): e21956.

48. Kumar S, Kumar V, Rana M, Kumar D. Enzymes inhibitors from plants: An alternate approach to treat diabetes. Phcog Commn 2012; 2(2): 18-33.

49. Natić M, Pavlović A, Bosco FL, Stanisavljević N, Zagorac DD, Akšić $M F$, et al. Nutraceutical properties and phytochemical characterization of wild Serbian fruits. Eur Food Res Technol 2019; 245: 46978.

50. Nowicka P, Wojdyło A. Anti-hyperglycemic and anticholinergic effects of natural antioxidant contents in edible flowers. Antioxidants 2019; 8: 308. 